\title{
The Impact Of Using YouTube In EFL Classroom On Enhancing EFL Students' Content Learning
}

Huda Omar Alwehaibi, Princess Noura Bint Abdulrahman University, Saudi Arabia

\begin{abstract}
Information technology has opened up prospects for rich and innovative approaches to tackle educational issues and provide solutions to the increasing demands for learning resources. YouTube, a video-sharing website that allows users to upload, view, and share video clips, offers access to new and dynamic opportunities for effective and non-traditional patterns of teaching and learning. In Saudi Arabia, this technology has not been exploited much for educational purposes. The present study aims at experimenting the impact of integrating YouTube technology into English as a foreign language (EFL) instruction on enhancing EFL college students' learning of the content of the course: "Observation in Schools 2". This course is one of five courses taught in the program "Elementary School Teacher of English" which aims at developing certain observation skills for effective teaching in elementary school. Such skills could include using particular frames or lenses to gain insight about the classroom and teaching and learning, and developing methods of observing and recording. For the purpose of the study, a quasi experimental design was adopted. Based on such design, two groups of second year college students at the Department of Curriculum and Instruction in the Faculty of Education at Princess Noura University in Riyadh, Saudi Arabia, were randomly assigned to the experimental and the control groups of the study. There were forty-five students in the control group and fifty-one in the experimental group. A pre-posttest covering the theoretical background of the course "Observation in School 2" was developed to be administered to all subjects of the sample before and after the experiment. Subjects of the experimental group were instructed the theoretical background of the course through the use of YouTube videos about observing the classroom, combined with discussion and power point presentation. Students of the control group were taught the same content through the usual lecture-based method. Instruction was provided to both groups by the researcher and took place throughout the second term of the academic year in 2011 for a period of 6 weeks, 2 hours per week. Statistical procedures were applied on the data obtained using a t-test, and major findings yielded results favourable to the use of the YouTube technology. The study shows positive gains for the experimental group students' outcomes as a result of the integration of video technology in instruction. Thus, it was recommended that YouTube should be considered as an effective instructional tool for enhancing content learning of EFL college students and as an important teaching resource in classrooms.
\end{abstract}

Keywords: YouTube; Educational Technology; Methods of Teaching; English as a Foreign Language (EFL)

\section{INTRODUCTION}

nformation technology has opened up prospects for rich and innovative approaches to tackle educational issues and provide solutions to the increasing demands for learning resources. The explosion of social media platforms in recent years as well as the proliferation of technological devices through which to communicate has revolutionised the global social sphere in the last decade. The potential impact upon the process of learning has also been studied, although it is perhaps surprising that there is a considerable paucity of research in this area. Nowhere is this more notable than in relation to YouTube. This literature will focus 
upon the variety of different ways in which the website can enhance the process of learning. It shows that the incorporation of YouTube in a language learning context, which is the focus of this study, is a vital prerequisite in a modern context.

In order to be able to understand how YouTube can enhance the process of learning, it is important to begin with a clear assessment of what YouTube represents. YouTube is a video-sharing website that allows users to upload, share and view videos (Dean, 2008, 231; Weinberg, 2009, 292). The website has been credited with being at the forefront of the social media revolution and the development of user-generated content, and has also led to a greater democratisation of society and empowerment of individuals in the view of some (Wankel, 2010, 113; House of Commons, 2007, 16). The wider revolution in social media and technological advances are highly relevant in educational contexts, where devices such as iPhones and iPads as well as Android devices offer a series of platforms alongside traditional ICT to assist the process of learning (Kitchenham, 2011, xxi; Reid, 2010; Nielsen, 2010).

There is a wide range of ways that YouTube can be utilised in order to assist and enhance the process of learning. Within the context of English language learning, YouTube is arguably even more useful than in other educational contexts and Alimemaj (2010) claims that technological advancements and the proliferation of broadband in traditional classroom situations means that English classes and learners have an enormously varied new tool to improve listening skills. She argues that this presents new challenges as well as opportunities, because even though YouTube offers a vast array of clips of authentic examples of 'everyday' English used by 'everyday' people within a wide range of contexts, the poor sound quality, pronunciation, and slang featured in many of these short videos can also make them more difficult to understand than traditional listening platforms (Alimemaj, 2010). Comac (2008) agrees with this assessment, but points to other important ways in which YouTube can improve the process of learning. She believes that YouTube offers an ideal platform through which to incorporate audio blogs into the classroom and instructors can use such blogs to manage oral assignments, interact with learners and to evaluate performance outcomes (Comac, 2008). Nejati argues that YouTube is critical, particularly in relation to enhancing future language learning, because such platforms play a "pivotal role in practicing the target language and its pragmatics, engaging students in active and productive projects, preparing them for likely future encounters in computer-mediated communication, learning more about other cultures and preparing them for becoming autonomous learners" (Nejati, 2010; Lord, 2009). However, whilst Nejati acknowledged the role that a wide variety of different websites can play, he is particularly emphatic about YouTube in a language learning context. He described YouTube as an "unlimited resource for language acquisition/learning" and points out that one can "listen to all kinds of spoken language (formal, neutral, informal) and genres (songs, parodies, debates, political speeches, talk shows, lectures) and learn a lot of vocabulary in context, which, without a doubt, will help memorisation" (Nejati, 2010).

Therefore it is clear that YouTube has an enormous potential to enhance the process of language learning with the manifold ways it can assist and improve listening skills for students. However, YouTube also has an important role to play in relation to reading comprehension and the use of YouTube texts, in particular, has proven to be particularly conducive to starting discussions and writing tasks (Rennie, 2012; Nejati, 2010). YouTube therefore is not only able to help by providing authentic texts and written material, but in relation to spoken English, is able to offer unique cultural dimensions to the spoken word, by highlighting not only academic English but also its application in real-life contexts, incorporating accents, slang and much else besides (Ghasemi, 2011; Derewianka, 2008).

Alimemaj (2010) argues that this is not only beneficial to the extent to which language learners are exposed to different styles of English and spoken English, but also points to another important dimension of YouTube assisted learning, namely the extent to which learners themselves can gain greater authority and autonomy when learning via this platform. In her study she interviewed groups of students and they pointed to YouTube as a "great online learning tool." For example, "it is useful for learning a language in and out of the classroom, you can find various styles and genres of the language, YouTube can help students explore the target culture in a variety of ways and it can help students develop their learning autonomy levels as it encourages them to watch videos and clips continuously" (Alimemaj, 2010). However, it is important not to overemphasise the autonomy of the learner and to point out that YouTube can also play a major role in enhancing the process of learning by assisting teachers in pointing to the world of online language learning and also by structuring their lessons in a more meaningful and 
interactive manner (Jarvis, 2004). This means that YouTube is able to enhance the learning process not only by providing alternative means for students and learners to engage with their material (something that some have referred to as positive spin-offs), but it is also able to strengthen the position of teachers by making their advice relevant and useful and by increasing the strength of their lesson structure and preparation (Paulsen, 2001; Alimemaj, 2010, 10). The combination of all of these ways in which YouTube can enhance the process of learning was predicted at a very early point by Paulsen and even before its advent she argued that "it is no longer a question of whether to take advantage of these electronic technologies in foreign language instruction, but of how to harness them and guide our students in their use" (Paulsen, 2001). The presence of YouTube and the multi-faceted way in which it can affect language learning within and outside the classroom means that this statement is even more accurate today than it was in 2001.

The ability of language learners to use this tool from a listening perspective is perhaps the most important advantage, but the benefits also extend to reading comprehension, greater student autonomy and enhanced lesson preparation and structure for teachers.

\section{Statement of the Problem}

In Saudi Arabia, this technology has not been exploited much for educational purposes. The present study aims at investigating the impact of integrating YouTube technology into EFL instruction on enhancing EFL college students' content learning.

\section{Research Question:}

The present study attempted to answer the following question:

- What is the impact of integrating YouTube technology into EFL instruction on enhancing EFL college students' content learning?

\section{METHODOLOGY}

\section{Design And Participants}

The present study investigated the impact of using YouTube to enhance EFL college students' content learning of the course: "Observation in Schools 2". This course is one of five courses taught in the program "Elementary School Teacher of English" which aims at developing certain observation skills for effective teaching in elementary schools. Such skills could include using particular frames or lenses to gain insight about the classroom and teaching and learning, and developing methods of observing and recording.

The quasi-experimental design adopted in this study was the "Non-randomized Control Group PretestPosttest Design" (Ary et al., 1996). Based on this design, two groups of EFL second year college students at the Department of Curriculum and Instruction in the Faculty of Education at Princess Noura University in Riyadh, Saudi Arabia, were randomly selected. Then, they were randomly assigned to the experimental and the control group of the study. There were forty-five students in the control group and fifty-one students in the experimental group.

Both groups studied the theoretical content of the course "Observation in Schools 2". Subjects of the experimental group were instructed through the use of YouTube videos about observing the classroom, combined with discussion and PowerPoint presentation. Students of the control group were taught the same content through the usual lecture-based method. Instruction was provided to both groups by the author and took place throughout the second term of the academic year 2011 for a period of 6 weeks, 2 hours per week. 


\section{Instrumentation}

\section{The Pre-Post Achievement Test}

A pre-post achievement test covered the theoretical content of the course "Observation in School 2" was developed by the author to be administered to all subjects of the sample before and after the experiment. It aims at assessing EFL students' learning of the theoretical background of the course, which covers mainly five different topics:
A. Characteristics of classrooms.
B. Goals of observation.
C. Lenses for classroom observation.
D. Making classroom visits.
E. Methods for observing and recording

The test consisted of 42 multiple choice items (with four choices each).

\section{Test Validity}

To determine its validity, the test was submitted to a number of specialists in English teaching methodologies, accompanied by a copy of the summary of the course content. In the light of their comments and recommendations, modifications were made.

\section{Test Reliability}

To determine the reliability of the test, the Pearson correlations were computed for each item. The test proved to be reliable.

\section{YouTube Videos}

Before the beginning of each class, the author searched YouTube for short videos of approximately 10-15 minutes on the topic that would be discussed. When an appropriate YouTube video had been selected, the URL of the video was sent to the students by email two days before the time of the class requesting them to watch it. At the time of the class, the author started the lecture with discussion of the topic outlining the main points to be covered through PowerPoint presentation. Then, the whole class watched the YouTube video on the data show in front of them, followed by questions and discussion. Then the video clip was shown again with frequent stops for further discussion. Some video clips have captions to summarize the topic of the scene, e.g., Lesson Observation: Tim Bedley Critical Thinking pt. (2008). Sometimes students paired up or sat in small groups and watched the video repeatedly to do some tasks related to the topic. At the end of the class, and as a home assignment, students were requested to go to YouTube and find a short video of their own to present to the class the next meeting.

\section{DATA ANALYSIS AND RESULTS}

To answer the research question: "What is the impact of integrating YouTube technology into EFL instruction on enhancing EFL college students' content learning?" an achievement pre-posttest was administered twice, before and after the experiment to assess learning of the theoretical content of the course by all participants.

\section{Results Of The Pre-Test}

Prior to the experiment, the pre-posttest was administered to all subjects of the sample in order to control for any initial differences between the experimental and the control groups. Thus, a t-test for independent samples was used to compare the mean scores of students in the two groups on the pre-posttest using the computer program SPSS (Ary et al., 1996). 
Table1 shows the difference between the mean scores of the experimental and the control groups on the pre-tests.

Table 1: Results Of The T-Test For The Mean Scores Of The Experimental And Control Groups On The Pre-Test

\begin{tabular}{clccccc}
\hline Test & Group & Number & Mean & Std. Deviation & t-test & Sig \\
\hline \multirow{2}{*}{ Pre-test } & Control group & 45 & 4.8222 & 3.35267 & 3.27 & 0.002 \\
& Experimental group & 51 & 2.8824 & 2.27725 & & Not Significant \\
\hline
\end{tabular}

Std. Dev. = Standard Deviation; Sig. = Level of Significance

As illustrated in Table 1, no significant differences were found between the mean scores of the students of both groups on the pre-test. It is evident that the experimental and the control groups were equivalent in their theoretical background knowledge of the course "Observation in School 2" before the commencement of the treatment.

\section{Results Of The Post-Test}

Attempting to reveal the differences between the two groups due to the integration of YouTube technology into EFL instruction, the same achievement test was administered as post-tests to both groups three days after the experiment. Then, a t-test for independent samples was used to compare the mean gain scores of the two groups on the post-test. The result is presented in Table 2:

Table 2: Results Of The T-Test For The Mean Gain Scores Of The Experimental And Control Groups On The Post-Test

\begin{tabular}{clccccc}
\hline Test & \multicolumn{1}{c}{ Group } & Number & Mean & Std. Deviation & t-test & \multicolumn{2}{c}{ Sig } \\
\hline \multirow{2}{*}{ Post-test } & Control group & 45 & 20.6444 & 6.11316 & \multirow{2}{*}{7.46} & $(0.00$ \\
& Experimental group & 51 & 28.9412 & 4.55373 & & \\
\hline
\end{tabular}

Std. Dev. $=$ Standard Deviation, Sig. $=$ Level of Significance

As shown in Table 2, t-value is significant at the 0.05 level for the total test score, a result that indicates the existence of statistically significant difference between the two groups on the post-measurements, in favour of the experimental group. Students in this group scored significantly higher than did students in the control group at 0.05 level on the post-test which indicates a positive impact of YouTube technology on enhancing the students' content learning. Figure 1 illustrates the significant difference between the two groups on the post-test.

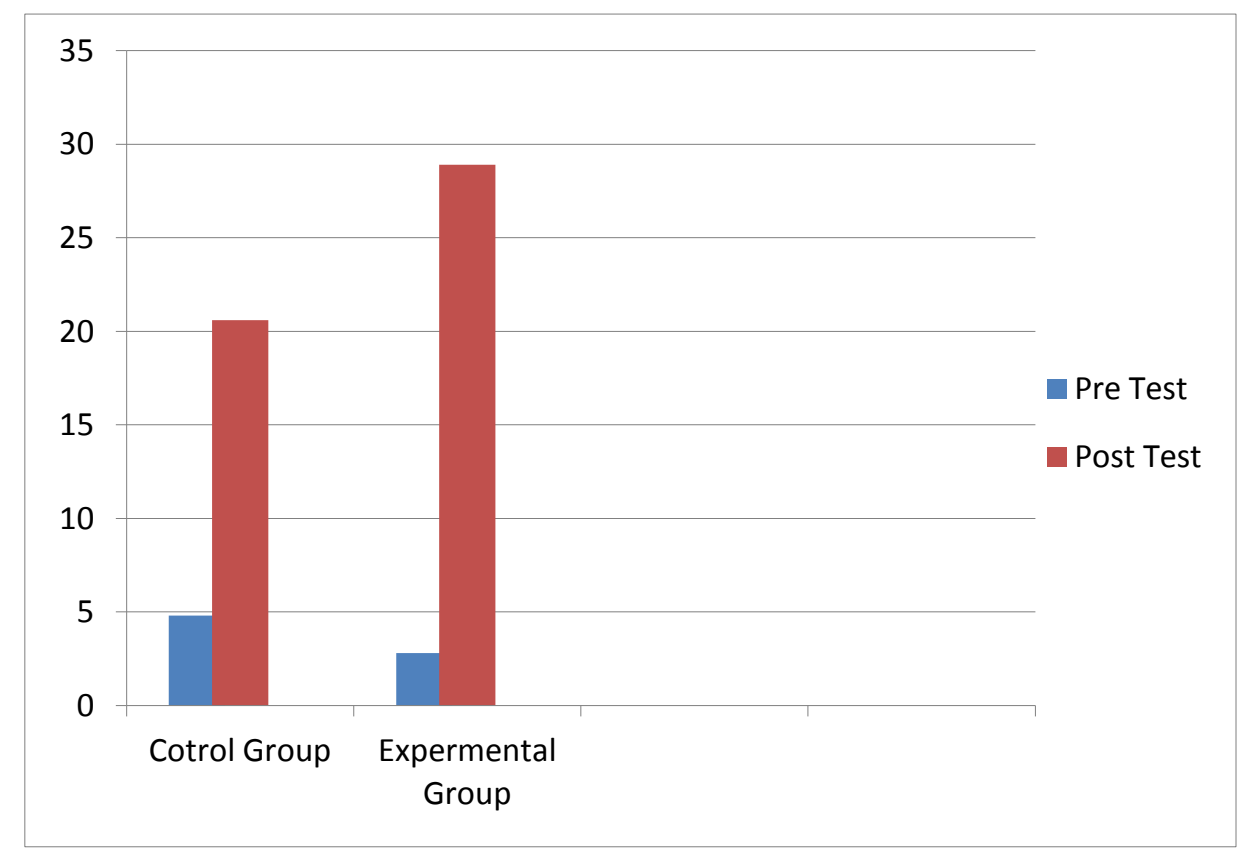

Figure 1: Mean Gain Scores Of The Two Groups On The Pre-Posttest 


\section{DISCUSSION OF THE RESULTS AND CONCLUSION}

The statistical analysis of the data using the t-test showed that YouTube had a significantly positive effect on EFL students' learning of the theoretical content of the course "Observation in School 2". This result supports various findings showing the positive impact of YouTube on enhancing students' learning. It has been clearly shown that YouTube can enhance the process of learning in a number of important ways. The enjoyable and entertaining atmosphere created by the use of YouTube motivated the students to learn. It was quite obvious that students in the experimental group were highly motivated to watch, read, write, discuss, interact and take part in the various activities throughout the learning process.

It is also important to note that the incorporation of Youtube into the classroom and outside the classroom is not without its challenges, but there is little question that the benefits of this technology far outweighs some of the problems associated with it. Therefore, the only question is how to incorporate YouTube, not whether doing so is a good idea, as the impact upon learning is too substantial to ignore. Thus, it is recommended that YouTube should be considered as an effective instructional tool for developing content learning of EFL college students and as an important teaching resource in classrooms.

\section{AUTHOR INFORMATION}

Huda Omar Alwehaibi, Ph.D., is an Assistant Professor of Curriculum and English Language Methodology and the Dean of the Community College at Princess Noura Bint Abdulrahman University, Riyadh, Saudi Arabia.

E-mail: hoalwehaibi@pnu.edu.sa

\section{REFERENCES}

Alimemaj, Z., 2010. Youtube, language learning and teaching techniques. AngloHigher, 2 (3), pp.10-12.

Ary, D., Jacobs, L., Razavieh, A., \& Sorensen, C. (1996). Introduction to research in education. New York, NY: Harcourt Brace College.

Comac, L., 2008. Using audioblogs to assist English language learning. Computer Assisted Language Learning, 21 (2), pp.181-198

Dean, M., 2008. Youtube. New York: O’Reilly

Derewianka, B., 2008. Venturing beyond Youtube. TESOL in Context, 18 (2), pp.42-72

Ghasemi, B., 2011. Utube and language learning. Procedia, 28, pp.63-67

House of Commons, 2007. New Media and Creative Industries. Westminster: TSO

Jarvis, H., 2004. Investigating classroom applications of computers on EFL courses at Higher Education institutions in the UK. Journal of English for Academic Purposes, 3 (2), pp.111-137

Kitchenham, M., 2011. Innovative techniques in instruction technology, E-learning, E-assessment and education. New York: Springer

Lord, G., 2009. The next generation. London: Routledge

Nejati, M., 2010. Annals of language and learning. London: Universal

Nielsen, K., 2010. Experiences obtained with integration of student response systems for ipod touch and iphone into e-learning environments. Journal of E-learning, 8 (2), pp.179-190

Paulsen, J., 2001. New era trends and technologies in foreign language learning. http://imej.wfu.edu/articles/2001/1/05/ Accessed 11/05/2013

Reid, D., 2010. iPod, iPhone and now iPad. World Conference on Educational Media, Hypermedia and Telecommunications, pp.2862-2864

Rennie, F., 2012. E-Learning and Social Networking Handbook. London: Routledge

Tim Bedley Critical Thinking pt. (2008) http://www.youtube.com/watch?v=0akVmCfUJiQ

Wankel, C., 2010. Cutting-edge social media approaches to business education. London: LAP

Weinberg, T., 2009. The new community rules. New York: O'Reilly. 